\title{
Los orígenes del pensamiento médico de Hipólito Unanue
}

\author{
Oswaldo Salaverry ${ }^{1}$
}

Resumen

Palabras clave

\begin{abstract}
Se revisa los orígenes y características del pensamiento ilustrado en la metrópoli española durante los siglos XVII y XVIII, y su relación con la génesis de las principales ideas médicas de Hipólito Unanue (1755-1833), introductor de dicho pensamiento en el Perú virreinal. Se muestra la incorporación de Unanue y su principal obra: "Observaciones sobre el Clima de Lima" en la tradición intelectual de las topografías médicas iniciada en Francia e Inglaterra y que tiene su primera expresión en todo el Imperio Español en este autor peruano, describiendo su particular incorporación de ideas ilustradas con el neohipocratismo, las que se mantendrán vigentes e influenciarán a la medicina peruana durante todo el siglo XIX y los primeros decenios del siglo XX bajo la forma de 'Geografía Médica'. Finalmente, se señala la aplicación de los conceptos médicos de Unanue en su reconocida participación en la reforma de la educación médica y en el apoyo a las medidas de implantación de la higiene en el virreinato.
\end{abstract}

Perú, historia de la medicina; Unanue, Hipólito; educación médica; medicina social.
The origins of Hipolito Unanue's medical thinking Abstract

The enlightenment thinking origins and characteristics in the Spanish metropolis during the XVII and XVIII centuries and its relation with Hipolito Unanue's (1755-1833) main medical ideas genesis introduced during Peru's viceroyalty is reviewed. Unanue and his main work "Observations on Lima's Climate" are integrated in the intellectual tradition of the medical topographies initiated in France and England and that had his first expression in this Peruvian author for all the Spanish Empire. We describe his particular incorporation of the enlightenment ideas to the neohippocratic movement, influencing Peruvian medicine during the XIX century through the first decades of the $X X$ century under the form of 'Medical Geography'. Finally we point out Unanue's recognized medical concepts application on medical education reform and his support to the implantation of hygiene measures during the viceroyalty.

Keywords: Perú, history of medicine; Unanue, Hipolito; education, medical; social medicine.

\section{Unanue y el pensamiento científico ilustrado}

La obra y el pensamiento de Hipólito Unanue han ejercido un rol central en diversos campos de la

Médico-Cirujano. UNMSM. Doctor en Medicina, Universidad de Salamanca. Catedrático de Historia de la Medicina. Facultad de Medicina de San Fernando, Universidad Nacional Mayor de San Marcos. Lima, Perú. evolución del pensamiento científico peruano desde fines del siglo XVIII, y con proyecciones que se puede identificar, específicamente en el ámbito médico, hasta fines del siglo XIX y comienzos del siglo XX. Su ubicación cronológica en el período en que se incorpora, tardíamente, el pensamiento ilustrado europeo en la élite criolla peruana amerita una mirada particularmente acuciosa a la génesis de sus ideas, ya que estas representan uno de los ejemplos más logrados de adaptación de las ideas ilustradas metropolitanas a la periferia científica. Esa misma posición privilegiada de su obra implica sin embargo dificultades por la diversidad de campos en los que se prodigó. Woodham, señala que en el Mercurio Peruano se encuentran aproximadamente 55 trabajos de Unanue, entre artículos y notas sobre los más diversos tópicos, de los cuales solo 8 son de carácter médico. Naturalmente, a esta recopilación debe añadirse obra dispersa y su obra cumbre de carácter médico "Observaciones sobre el Clima de Lima" $\left.{ }^{1}\right)$. A pesar de la estrecha vinculación entre su pensamiento científico y su pensamiento social y económico, debemos excluir de los alcances del presente trabajo la vertiente política de su pensamiento *, a pesar que este último, en gran medida es sólo una expresión del primero. En segundo lugar, el presente trabajo, aunque se centra

Se puede revisar al respecto a Alayza y Paz Soldán, $L$. Unanue, San Martín y Bolívar. Lima, 1934. 
en las ideas estrictamente médicas presentes en su obra, inevitablemente se vincula con sus ideas naturalistas. Sin pretensión de agotar todas las facetas de su pensamiento médico, se revisará fundamentalmente la tradición intelectual en la que se inserta su obra principal y su estrecha vinculación con la escuela médica denominada higienista, en su formato inicial, basada en las topografías médicas.

\section{La filiación teórica del pensamiento médico de Unanue}

Al tratar el pensamiento médico de Unanue, la historiografía tradicional ha insistido en su carácter renovador de la educación médica $\left(^{2}\right)$, centrándolo en el impulso que le dio a la anatomía. Una referencia menor se hace a su rol de introductor del pensamiento newtoniano, punto en el cual, en todo caso, tuvo como predecesor a Cosme Bueno $\left(^{3}\right)$. También, se ha indicado su rol de introductor de la sistematización de la botánica aplicada o materia médica y, naturalmente, su reconocido papel en la defensa del carácter singular de las enfermedades y de su tratamiento dependiente de esa misma singularidad, lo que aplicó específicamente al caso de Lima. Pese a esa adecuada caracterización, poco se ha hecho para entroncarlo en la tradición intelectual europea de las topografías médicas o, con mayor amplitud, en incorporarlo en la tradición de la medicina ilustrada europea. Pareciera que Unanue y su obra súbitamente aparecen en la medicina peruana con una obra localista, la por demás celebrada "Observaciones", que en la propia metrópoli es considerada por los comentaristas como una innovación. La tradición historiográfica le atribuye como únicos antecedentes reconocibles la obra de Gabriel Moreno, Cosmógrafo del Reino, Catedrático de Prima de Matemáticas y su profesor en San Marcos y, más en lontananza, la influencia de Cosme Bueno, el cosmógrafo aragonés de quien fue discípulo Moreno y que llegó a conocer Unanue en sus años de estudiante.

Ha contribuido a consolidar este supuesto aislamiento de otras influencias la exitosa fórmula literaria con que Paz Soldán intenta establecer la secuencia generacional de la medicina peruana, llamando a Unanue el padre de la medicina peruana y a Cosme Bueno el abuelo de la misma, frase que por su fácil recordación caló profundamente en la general superficialidad con que se ha tratado la investigación de la historia del pensamiento científico peruano, que se limita en la mayoría de los casos a un estudio de personajes, sin profundizar en las tradiciones científicas que enmarcan toda obra individual $\left({ }^{4}\right)$.

Frente a este panorama, es necesario establecer la vinculación del pensamiento médico de Hipólito Unanue en la tradición intelectual de la época, ubicando las ideas centrales de su pensamiento médico y rastreando en cada caso el probable origen de las mismas en esa tradición. Pero, esta tarea es imposible sin abordar, aunque sea sucintamente, un problema de mayor complejidad, como es el identificar las características de la ilustración criolla en el Perú colonial de la segunda mitad del siglo XVIII.

\section{El pensamiento ilustrado y su versión Ibérica}

A fines del siglo XVII, se inicia en Europa la difusión de una nueva corriente filosófica, la cual, basándose en la razón y los logros de la revolución científica, da origen a una crisis intelectual que cuestiona la base de las creencias teológicamente fundamentadas, que habían permanecido durante todo el medioevo y el renacimiento sin sufrir mayor modificación. La llamada 'crisis de la mentalidad europea' se asocia a la difusión del cartesianismo y su 'filosofía mecanicista', la que en su versión más conocida se difunde por toda Europa, supuestamente desde su origen en Francia. En realidad, el proceso fue mucho más complejo y la 'nueva Filosofía', si bien tiene uno de sus centros en Francia, no tuvo una versión única ni un solo centro; adoptó una versión diferente en Inglaterra y variaciones locales en Europa continental $\left({ }^{5}\right)$. De las diversas formas en que la 'nueva Filosofía' se articuló en cada una de las sociedades occidentales, se obtiene variantes locales de asimilación, las que luego darían lugar a las variantes nacionales de la Ilustración.

Siguiendo a Israel $\left({ }^{6}\right)$, se identifica al menos cinco corrientes simultáneas compitiendo entre sí por obtener la supremacía en la explicación 'ilustrada' del mundo: el neo Aristotelianismo, el neo Cartesianismo, el Leibniz-Wolffianismo, el Newtonismo y lo que él denomina el 'radicalismo ilustrado', basado en la obra de Baruch Spinoza ${ }^{\dagger}$. Esta diversas corrientes intelectuales, sin embargo, no actuaron todas en España y mucho menos en los

Baruch Spinoza, (1632-1677). 
territorios ultramarinos del Imperio Español. La política de aislamiento que la metrópoli mantenía desde la época de la contrarreforma en todos su territorios y su control adicional en América, que limitaba desde las autorizaciones de viaje hasta las importaciones de libros, nos alejó de la disputa de estas diversas corrientes. En realidad, en América solo se conoció una de las versiones de la Ilustración, la Ibérica, y esta no correspondió a la Ilustración continental y francesa sino a la británica, alejada del racionalismo francés y cartesiano y directamente emparentada con el empirismo inglés y las doctrinas de John Locke. Los extraños caminos por los que una versión ilustrada procedente de un país no católico y además enemigo de España durante casi todo el periodo se convierte en la corriente intelectual hegemónica en España y América, merecen ser someramente revisados.

En los inicios de la difusión del cartesianismo en España, tuvieron un rol muy importante las obras del fraile mínimo Emmanuel Maignan, quien enseñó Filosofía durante muchos años en Toulouse, y que, si bien se definía como anti Aristotélico y cartesiano, era por decir lo menos un cartesiano peculiar, pues no aceptaba la doctrina de la dualidad de la sustancia de Descartes ${ }^{\ddagger}$ y asumía en cambio una suerte de atomismo. Precisamente, su peculiar cartesianismo hizo que sus doctrinas tuvieran acogida en el cerrado y conservador círculo intelectual y religioso ibérico. Maignan afirmaba que la Teología enseñaba la esencia de la verdad, pero que la nueva filosofía, es decir la cartesiana, adquiría un carácter esencial, pues al mostrar un dios providencial y demostrar que la naturaleza tiene un plan general, se tornaba, de filosofía común, en 'Filosofía sagrada', precisamente el título de su obra más conocida 'Philosophia sacra', de 1661. Esta aproximación a la nueva filosofía que trataba de mantener los dogmas del catolicismo al tiempo que asumía las características de la racionalidad, signaría la peculiar forma en que se plasmaría la Ilustración Ibérica $\left(^{7}\right)\left({ }^{8}\right)$.

Sin embargo, no todos los intelectuales españoles coincidían con las ideas de Maignan. En 1686, el médico valenciano Juan de Cabriada (1665-1715) publica su conocida "Carta filosófica medico- chymica" \$, punto de inicio del llamado movimiento novator o innovador. En su carta, que por cierto recibió todas las licencias eclesiásticas, colocaba como ejemplo de filósofos a personajes como Robert Boyle, Stenon, Thomas Willis, Thomas Sydenham y Franciscus van Helmont, personajes todos de clara raíz mecanicista y representantes de lo que se ha denominado el iatromecanicismo. Su ataque a los médicos galenistas fue frontal, atribuyéndoles el atraso de la ciencia española y proclamando que la razón y la experiencia y no la sujeción a la autoridad son las bases del desarrollo científico $\left({ }^{9}\right)$. Su posición fue duramente combatida, incluso por quienes luego se adhirieran a la doctrina de los novatores, como Diego Mateo Zapata (1644-1745), médico también y que, formado como galenista, llegó junto con los representantes más recalcitrantes del galenismo ibérico a negar la circulación de la sangre demostrada por Harvey $\left({ }^{10}\right)$. Años después, Zapata se convertiría a las nuevas doctrinas y sería promotor de la fundación de la 'Regia Sociedad de Medicina y demás Ciencias de Sevilla', en 1700, que con el patrocinio de Carlos II se convertiría en el foco de la difusión de la ciencia moderna en España.

El cambio de siglo coincidió con la cruenta guerra de sucesión española, al haber quedado sin descendencia la dinastía de los Habsburgo. Desde 1702 hasta 1714 , cuando culmina la guerra con la captura de Barcelona y el triunfo de la nueva dinastía Borbónica, las instituciones, universidades y naturalmente las actividades científicas sufrieron un receso, que incluso afectó las comunicaciones e intercambio de información con el resto de Europa $\mathrm{y}$ las posesiones americanas $\left({ }^{11}\right)$. El nuevo monarca de la dinastía Borbón, Felipe V, se dedicó a consolidar y centralizar la autoridad real y el poder eclesiástico. Para ello, restableció los poderes de la Inquisición que durante la guerra de sucesión casi no había actuado y alentó una amplia represión de las ideas que podían cuestionar la autoridad, entre las cuales ocupaba un lugar preeminente las del mecanicismo cartesiano, vinculándolo en muchas ocasiones con el cripto-judaísmo $\left({ }^{12}\right)$.

En los siguientes años, una larga y acre polémica entre los novatores y los aristotélicos originará el

\footnotetext{
* Descartes consideraba que la realidad estaba compuesta de dos tipos de sustancias, la res cogitans y la res extensa, mente y materia, las cuales no tienen relación alguna entre sí, excepto en el hombre, en el cual por voluntad divina, una tiene influencia sobre la otra. Descartes creyó encontrar en la glándula pineal el punto de comunicación entre las dos sustancias.

$\S$ El original de la "Carta", puede ser consultada en la Biblioteca de la Universidad Complutense. Madrid.
} 
peculiar modo de la ilustración española. Y, aunque sin duda este es un proceso con múltiples actores, destaca el rol de Gabriel Álvarez de Toledo, quien publica, en 1714, su "Historia de la Iglesia y del Mundo" ". En la "Historia..." se evidencia su credo mecanicista, pero al mismo tiempo su creencia en los ángeles como seres libres de todo elemento material, espíritus puros y por tanto exentos de toda corrupción. La respuesta de los escolásticos conservadores a este intento de promover la conciliación entre las ideas ilustradas y la religión, fue dada por un fraile, que luego sería electo Obispo de Panamá, Francisco Palanco (1657-1720), quien escribió su Dialogus physico-theologicus contra philosophae novatores; explícito desde el título. En él, Palanco denostaba de los seguidores de esa nueva filosofía representada por Maignan, Descartes y Gassendi y liderada en España sobretodo por physicos, o médicos, quienes con su 'seudo philosophia' propiciaban la destrucción de la fe, la autoridad y la Iglesia. Las acusaciones eran demoledoras en el ambiente lleno de suspicacias de la época; y, por eso, la respuesta de los seguidores de Cabriada fue no solo no aceptar el epíteto de novatores que sus detractores aristotélicos habían conseguido convertir en sinónimo de subversivos de la fe y el orden, sino adoptar una forma ecléctica o empirista de la Nueva Filosofía. Eso queda muy claro, sobretodo en la obra de Juan de Nájera, quien con el seudónimo de Alejandro de Avendaño escribió unos «Diálogos filosóficos», en 1716, en los cuales defendía la posición ilustrada de Maignan, pero aceptando la peligrosidad del pensamiento cartesiano. Otro de los defensores de la Nueva Filosofía fue Diego Zapata, que luego de su inicial oposición a la Nueva Filosofía, adopta la posición de defensor de la misma. Precisamente, en el prefacio de los "Diálogos Filosóficos" de Nájera escribe: "No soy un cartesiano, pero si un amante de la razón y la verdad". Zapata, que era un judío converso, es perseguido por la Inquisición y, a mediados de 1725 , luego de culminar su obra más sólida pero que no publicaría en vida ("Ocaso de las formas aristotélicas") fue arrestado, torturado y obligado a confesar que a los 12 años fue iniciado en la religión judía por su madre y que seguía practicando sus ritos, incluso cuando ejercía de médico en Madrid. Su obra "El Ocaso..." sienta las bases de la particular forma que asumirá la ilustración española; y, aunque solo se publicara en 1745 , poco después de su muerte, parece que circulaba en forma manuscrita desde que la terminó. En su obra, Zapata exalta al 'inmortal filósofo católico Descartes' y trata de demostrar que la libertad de filosofar no representa alguna amenaza para la fe y que, por el contrario, es esencial para el bienestar de la nación española. Respondiendo a la tradicional acusación de faltar el respeto a los padres de la Iglesia, afirma que en "asuntos exclusivamente filosóficos" disentirá de la opinión de cualquier Padre del Iglesia, siempre que la razón lo obligue a ello, ya que si en la Teología la libertad para debatir y la libertad de opinión es peligrosa, no hay ningún riesgo o daño en la libertad de filosofar. Insiste en que Dios inspira a los padres de la Iglesia solo en las materias sagradas, ya que no se requiere que por una ciega deferencia esta inspiración se extienda a otras materias. Por consiguiente, reclama la total separación entre Filosofía y Teología ".

La respuesta por parte de los escolásticosaristotélicos vino de Juan Martín de Lessaca, profesor de medicina en la Universidad de Alcalá de Henares y enemigo declarado del cartesianismo y del criptojudío Zapata. Lesaca rechaza la libertad de filosofar reafirmando la antigua doctrina escolástica que subordinaba la Filosofía a la Teología (Philosophia ancilla Theologique). Culminaba Lesaca su alegato insistiendo en que una vez que los españoles aceptaran la ficción de que no hay riesgo en cualquier método de filosofar, sería imposible mantener las ideas radicales alejadas de España $\left({ }^{13}\right)$.

Correspondería zanjar las disputas y culminar la difusión de las ideas ilustradas, en la peculiar forma que ya se ha indicado, a Benito Jerónimo Feijoo y Montenegro (1677-1764), monje Benedictino, con su obra monumental, "Teatro Crítico Universal” **,

1I Gabriel Álvarez de Toledo y Pellicer era un noble muy cercano a la corte de Felipe V; caballero de la orden de Alcántara, erudito y de amplio criterio, dominaba el latín, griego hebreo y árabe. En su casa en Madrid (era originario de Andalucía), se reunían bajo su protección diversos eruditos interesados en la Nueva Filosofía. Su alto rango lo protegía hasta cierto punto de la Inquisición, pero su obra "Historia de la Iglesia y del mundo", Madrid, 1713, fue motivo de furibundas críticas.

1 Ver Zapata, 1690 ob. cit. p. 370.

** Los ocho tomos de Teatro Crítico Universal fueron publicados entre 1726 y 1736 y editados reunidos en 1773. 
y "Cartas eruditas y curiosas" $\pitchfork$. Debe notarse que es uno de los autores constantemente citados por Unanue y presente en su Biblioteca $\left({ }^{14}\right)$. La influencia de las ideas ilustradas en España y sus territorios se debe fundamentalmente a este monje. Y, tal como lo señala el censor del sexto volumen del "Teatro", Dr. José Elizalde (quien por cierto fue rector de la Universidad de México), su influencia había transformado el modo de pensar de todos, no solo en España sino en los Virreinatos de Nueva España y Perú, y hasta en lugares tan alejados como Filipinas $\left({ }^{15}\right)$. Se puede decir que, para fines de 1730, a través de la influencia de Feijoo, el Newtonianismo se había asentado entre los ilustrados en ambas orillas del Imperio Español, las sociedades más rígidas del catolicismo. Su influencia, sin embargo, fue más allá, criticando la posición extremadamente conservadora de las Universidades y sus catedráticos que impedían el desarrollo de las Ciencias $\left({ }^{16}\right)$. Feijóo introdujo en España la convicción de que solo el Newtonianismo y la escuela empírica inglesa dotaba a los fieles súbditos y fervorosos católicos españoles del bagaje intelectual y conceptual para defender la fe en los milagros y protegerse de los filósofos materialistas $\left({ }^{17}\right)$. Así, el Empirismo y en general los autores británicos moldearon la Ilustración Ibérica y virreinal, marginando a autores franceses y de la órbita germana, como Malebranche y Leibniz, y resguardándose de Bayle, cuya erudición admiraban pero cuyas ideas eran consideradas peligrosas $^{\text {. }}$

En el campo específico de la medicina, la influencia de Feijóo también se hizo sentir, especialmente con una de nombre elocuente, "De lo que sobra y falta en la enseñanza de la Medicina" $\left({ }^{18}\right)$, que prefigura lo que serían las reformas de la educación médica que son implantadas en España a fines del siglo XVIII. La culminación de esta entronización de una ilustración ibérica es un edicto de Fernando VI, del 23 de junio de 1750, que proclama que las obras de Feijóo y las que contengan ideas semejantes a las suyas tienen la completa aprobación de la Corona y que por tanto deben cesar todos los ataques contra ellas.

\section{Las topografías médicas}

Definido el campo en el cual Unanue y los otros ilustrados criollos se desarrollan, debemos revisar los temas fundamentales de su pensamiento médico y delinear aproximadamente su vinculación con la tradición intelectual correspondiente. En primer lugar, debemos señalar que el propio Unanue tenía plena conciencia de su vinculación con una corriente de pensamiento médico ilustrado. En ningún momento, su obra pretende ser original; por el contrario, orgullosamente en la segunda edición de "El Clima de Lima..." $\left({ }^{19}\right)$, cita, por natural búsqueda de aprobación, el favorable comentario que despierta su obra en España. Explícitamente, se reconoce que su obra está enmarcada en los desarrollos de las topografías médicas, que desde mediados del siglo XVIII se desarrollan en Francia e Inglaterra. Sigamos la ilación de Unanue. De una reseña, toda ella encomiástica, publicada en el memorial Literario de Madrid, en mayo de 1808 , referidas a la $1^{\text {a }}$ edición de "El clima de Lima...", extracta lo siguiente: "sus observaciones [...] no solo tienen el mérito de de la originalidad, sino el haber tratado esta materia con un orden científico y, cuando no más, con tanta filosofía y crítica como la que tienen los escritos de esta clase publicados en Europa, a lo menos los que yo conozco" * .

Es evidente pues que el comentarista conocía de una corriente médica, sin cultivadores aun en España, de la que la obra de Unanue era pionera en el ámbito hispanoamericano. Pero, no terminan allí los interesantes extractos. Unanue continúa escogiendo con tino los párrafos que a su entender llevaban los mayores elogios; cita así este otro juicio: “...no dudamos en afirmar que es uno de los mejores tratados que sobre este particular se han escrito en nuestros días, y que nos deberíamos dar por muy satisfechos con tal que le imitara alguno de nuestros ilustrados profesores que gozan de pública reputación".

No puede dejar de aparecer la nota ácida, del anónimo comentarista hispano, totalmente dirigida al público metropolitano en tono de casi reproche: “... es, en verdad, muy extraño que, llevando

${ }^{\dagger}$ La primera edición reunida de las “Cartas eruditas y curiosas” es la de Madrid 1774, en 5 volúmenes; pero, la difusión de las mismas se realizó durante casi treinta años en vida de su autor.

\# Ver Israel 2002. Ob. cit. P. 536.

* Unanue Ob. Cit. P 41. 
nosotros a los peruanos muchos siglos adelantados en la ilustración y bastantes años en la erección de Cátedras de todas clases, se haya publicado el primer libro de esta clase en Lima y no en Madrid".

Pero, ¿a qué clase de trabajos pertenecía esta obra de Unanue? Aunque nunca denominada con ese nombre en los estudios sobre la historia de la ciencia peruana, nos referimos al 'Higienismo', movimiento que tendrá su pleno desarrollo en el XIX, pero que en su versión inicial, desde mediados del siglo XVIII, se plasmó en las llamadas 'Topografías médicas'.

Para encontrar los referentes inmediatos de esta corriente, debemos remitirnos a las publicaciones que a lo largo de la segunda mitad del XVIII aparecen en Inglaterra y Francia, en el primer caso con los trabajos de Cleghorn, Hillary ${ }^{\dagger}$ Rutty y R. Jalison y, en el segundo, a la Topografía de París por Meneuref, en 1786, los trabajos de Lepecq de la Cloture sobre Normandía (Rouen), en $1778^{*}$, la monografía de Souquet sobre el distrito de Boulogne, de 1791, y la Topografía médica de Montpellier confeccionada por Murat $\left({ }^{20}\right)$. No hay evidencia alguna que Unanue hubiera tomado conocimiento directo de estos autores y sus Topografías.

Cabe preguntarse en ese caso de dónde provenía la influencia que da origen a la topografía limeña que conocemos por "El clima de Lima" y que además es la base de su pensamiento médico. Las constantes alusiones a Sydenham en la obra de Unanue nos dan la pista: En efecto, el médico inglés Thomas Sydenham (1624-1689), por cierto en la órbita de los autores que el anglicismo de la Ilustración oficial fomentaba, al estudiar la epidemia londinense de 1660, que duró diez años, encontró variaciones cíclicas en la morbilidad y mortalidad, lo que correlacionó con las condiciones del clima que se presentó en el período; fuertemente influenciado por el neo hipocratismo de la época, toma la vieja idea de katastasis presente en el Corpus Hippocraticum, particularmente en "Sobre los aires las aguas y los lugares" y le da nueva forma como "constitución epidémica' $\left({ }^{21}\right)$.

Basándose en lo anterior, Sydenham introduce una nueva clasificación de las enfermedades agudas o febriles, las que clasifica en epidémicas, estacionarias, intercurrentes y anómalas. Las epidémicas serán "las determinadas por una alteración secreta e inexplicable de la atmósfera", mientras que las estacionarias se las atribuye a "una oculta e inexplicable alteración acaecida en las entrañas mismas de la tierra". Se reactualiza así la concepción ambientalista de la medicina hipocrática, ligándola a los desarrollos de la revolución científica con la cuantificación y la medida.

La expresión de este nuevo acercamiento a las enfermedades agudas conduce a las topografías médicas, que surgen así como consecuencia lógica de la doctrina de las constituciones. La topografía médica identifica los lugares saludables y los diferencia de los malsanos, distingue las zonas en que es posible habitar y aquéllas que deben ser evitadas. Más aún, determina un método a través del cual la medición de las variables meteorológicas (temperatura, humedad, presión atmosférica, orientación del viento) y climáticas de un área, es la condición previa para establecer correlaciones con las 'fiebres' del lugar, y el 'temperamento' de sus habitantes, posibilitando así una acción terapéutica eficaz.

Meneuref, en 1786, lo explicita claramente: "Es bien cierto que existe una cadena que vincula en el universo, en la tierra y en el hombre, a todos los seres, a todos los cuerpos, a todas las afecciones: cadena cuya sutileza al eludir las miradas superficiales del minucioso experimentador y del frío disertador descubre al genio verdaderamente observador".

Ya desde 1776, Hautesierck había propuesto a los médicos y cirujanos militares franceses un plan de trabajo extremadamente ambicioso, que comprendía el estudio de las topografías de toda localidad francesa, es decir de la situación de los lugares, el terreno, el agua, el aire, la sociedad, los temperamentos de los habitantes; el cual debería completarse con observaciones meteorológicas (presión, temperatura, régimen de vientos), análisis de las epidemias y de las enfermedades recurrentes, así como la aparición de casos extraordinarios.

Encontramos ahora a Unanue desarrollando, en una colonia periférica y antes que en su metrópoli

El título de la obra es "Observations on the changes of the air and the concomitant epidemic diseases in the island of Barbados" London. 1759.

* Esta obra, cuyo título completo es “Collections d'observations sur les maladies et constituions èpidémiques”, es el más claro ejemplo de topografia médica y un modelo muy semejante al desarrollado en España. 
política, la idea de constituciones epidémicas y de la medicina topográfica. Pero, antes de seguir adelante, debemos precisar el concepto de clima, tan íntimamente vinculado a las topografías médicas. Pedro de Lucuce, en su Tratado de cosmografía de $1776\left({ }^{22}\right)$ indica: "Generalmente se dice clima el espacio comprendido entre dos paralelos, cuyos habitadores tienen el día mayor del año con algún exceso notable como de media hora o una hora; por ejemplo, si en un paralelo el día mayor del año es de 13 horas y en otro de 13 y 1/2 horas, las regiones situadas entre estos paralelos se dice que están en un mismo clima. Vulgarmente llaman de diverso clima a dos regiones en quienes es diverso el temperamento de calor, frío, humedad o sequedad, pero esto no se ha de entender así en términos de Geografía”.

Es decir que, lo que hoy entendemos por clima los aspectos meteorológicos- tenía una acepción técnica totalmente diferente en el siglo XVIII; y así debemos entender el objeto de la obra principal de Unanue "Observaciones sobre el clima de Lima y su influencia en los seres organizados, en particular el Hombre". Pero, para identificar la génesis de sus ideas, considerando que el "Clima de Lima" es una obra de síntesis y madurez, publicada en 1806, debemos referirnos a dos artículos publicados en El Mercurio Peruano, en 1792, en los que se puede identificar el paulatino acercamiento a su visión final de la medicina topográfica: "Precauciones para conservar la salud en el presente otoño" ( ${ }^{23}$ ) y luego "Resultado del pronóstico y precauciones para el otoño" $\left({ }^{24}\right)$. En el primero, y como introducción general al fondo de su artículo que es la constitución médica del otoño (la catástasis se podría decir), da una explicación sobre la benignidad del clima de la costa peruana "porque la ventajosa posición de nuestra deliciosa Patria elude el furor de la zona que habitamos".

Las causas concretas para el singular clima de Lima, serían: "La distancia de los cerros y arenas que podían rechazar los rayos solares, el terreno circunvecino propio para absorberlos, la arboleda que lo hermosea, el Sur [refiriéndose al viento que sopla del sur] que, aunque blandamente, no ha cesado de ventear, son las causas benéficas que nos han preservado, no solo de morir sofocados, sino aún, de aquellas epidemias, que en otros años hacen temible el Estío".

El objeto del artículo es advertir al público que la excelente sanidad que se ha observado en el verano de 1791, no debe hacer suponer que continuará igualmente en el otoño que se avecina; pues advierte que: "Nuestros humores no están a la misma disposición que a la entrada de la estación presente [al momento de publicarse el artículo en el Mercurio Peruano, Lima aun se encontraban en Verano]. Se hallaban entonces depurados en cierto modo por la benigna influencia que experimentamos en la primavera y con la humedad correspondiente para embotar la fuerza del fuego. El incremento y continua acción de este, a propósito que abanzaba [sic] el Estío, los ha dexado de suerte que se encuentra hoy la sangre casi sin jugo, cargada de partículas térreas, alterada la cólera, y los sólidos floxos y desecados".

La alusión a los humores y a términos técnicos deudores de la tradición galénica es expresión de la tardía renovación del vocabulario técnico médico y ha conducido a que algunos autores que analizan la obra de Unanue concluyan, muy superficialmente, y a partir de las aparentes contradicciones, que coexisten en Unanue no solo términos sino fundamentalmente los conceptos galénicos junto con solo algunos modernos; sin considerar que ese es un problema general de la época, que no logra en ninguno de sus representantes concretar una nueva y coherente teoría que explique todos lo fenómenos tan bien como lo logra la teoría galénica ${ }^{\S}$. Lo que en realidad sucede es que se continúa usando los términos técnicos galénicos, pero con cambios en el concepto al que apelan, adaptándolos en algunos casos a las nuevas ideas y conceptos desprendidos de las escuelas sistemáticas del XVIII, todas ellas deudoras por cierto del neo hipocratismo.

Aunque repetido muchas veces, debe anotarse una vez mas que reemplazar el sistema galénico no era tarea fácil $"$. Las ideas galénicas tenían una gran capacidad explicativa para los fenómenos que se observaba, un enlace coherente con una cosmología y una concepción científica general. Si bien ya desde

$\S \quad$ En particular este error es patente en Woodham quien niega que con Unanue se realice una verdadera renovación de la medicina en el Perú.

II Una buena aproximación al pensamiento galénico es el clásico libro de Siegel "Galen's system of Physiology and medicine. An analyis of his doctrines and observations on bloodflow respiration, humors and internal diseases". Karger, Basel, 1968. 
el siglo anterior el edificio completo presentaba grandes e insuperables grietas que amenazaban con derrumbarlo, no existía, y continuaría sin concretarse un nuevo paradigma coherente y explicativo hasta bien entrado el siglo XIX; paradigma en el cual aún nos encontramos inmersos.

Es por eso que, en el concepto de vida que esboza Unanue en este texto, encontramos indudables deudas a los conceptos aristotélicos, pero colocados en un contexto distinto "; en este punto, no se aparta de la explicación más consistente en la época para el fenómeno de la vida. Dice Unanue: "Vivimos por el movimiento que hace circular los líquidos del cuerpo humano, y evaporar sus partes heterogéneas [sic]. El calor es su principal agente y conservador, siempre que no excede los límites que le tiene prescritos la naturaleza para perpetuar la salud. En saliendo de ellos se expone a una muerte inevitable, o a varias dolencias que la preceden" ${ }^{* *}$.

El rol fundamental del calor en la génesis y mantenimiento de la vida es propio del sistema galénico. Pero, en este caso incorpora una explicación que lo distancia completamente de la fisiología galénica: se produce en el interior del cuerpo humano, por una combustión idéntica en su sentido a la combustión inorgánica, pero peculiar en los seres vivos (una combustión sin llama, menciona Galeno). La principal y, para algunos, única fuente del calor animal era el ventrículo izquierdo y de allí se distribuye a todo el cuerpo a través de la sangre. El problema fundamental es mantener la temperatura estable en todo el cuerpo, lo que se explica por la acción de la respiración, que se reconoce como imprescindible para la vida. Pero, desconociéndose aún el rol del oxigeno y de los procesos de generación de energía por oxidación, se consideraba que su función vital era derivada de una de las características evidentes empíricamente del aire: su capacidad de enfriar lo que rodea, como su rol fisiológico fundamental. Así, la respiración tendría por principal objeto enfriar el calor producido en el ventrículo derecho ${ }^{\dagger \dagger}$.

Al parecer, Unanue concordaba con el concepto galénico de la importancia fundamental del calor y de los extremos en los que debe mantenerse para preservar la salud. Pero, en él es evidente que otros complementos del sistema galénico ya han sido desechados; por ejemplo, Unanue acepta plenamente que la sangre circula impulsada por las contracciones cardiacas, tal como lo descubriera Harvey, más de un siglo antes. Debe recordarse que, en San Marcos, sin duda con gran retraso, se efectuó una clase especial para explicar la teoría de la circulación de Harvey. En el sistema galénico, la sangre circulaba empujada, desplazada por el aire.

El concepto de Unanue de la composición de la sangre continúa siendo, en lo fundamental, galénico. Pero, se menciona otros componentes, reflejando así un proceso de incorporación de los nuevos hallazgos de la ciencia, pero en un esquema estructural al menos parcialmente subsistente. Hace así referencia a un componente 'jugo' (debe entenderse tal vez como agua, bien en su condición de elemento o principio o en su concepción más material de sustancia acuosa), así como también a 'partículas térreas', 'cólera' y 'sólidos'. Las partículas térreas sin duda aluden a

- Aristóteles, en uno de los breves tratados agrupados como los parva naturalia y denominado "Acerca de la Juventud, y de la vejez, de la vida y de la muerte, y de la respiración", dice lo siguiente: "Todas las partes y todo el cuerpo de los animales tienen un cierto calor natural congénito, por ello se muestran calientes mientras están vivos, pero, al morir y quedar privados de vida, lo contrario. Es forzoso, por tanto, que el principio de este calor resida en el corazón de los animales que tienen sangre, y en la parte análoga en los que no la tienen, pues todas ellas elaboran el alimento y lo digieren gracias al calor natural, principalmente la parte más importante. Por ello, aunque se enfríen las demás partes, persiste la vida, pero, cuando esto sucede con el corazón, se destruye por entero, porque de ello depende el principio del calor para todas las partes y el alma esta como ardiendo en ellas, es decir, en el corazón en los animales que tienen sangre, y en lo análogo en los que no la tiene. Por lo tanto, es forzoso que la vida y la conservación del calor se den a la vez y que lo que llamamos 'muerte' sea la destrucción de este calor". Aristóteles. Acerca de la juventud, y de la vejez, de la vida y de la muerte y de la respiración. En: Parva naturalia. Madrid: Biblioteca Clásica Gredos. 1987;107:325-326.

*** Cit. Pág. 6.

${ }^{\dagger}$ Recuérdese que el concepto original galénico es previo a un completo conocimiento de la anatomía y fisiología circulatoria, por lo que la conexión entre la vena pulmonar y el ventrículo izquierdo era la evidencia anatómica de que el aire ingresado por los pulmones tenía una función que cumplir en la cámara derecha del corazón, la cual debía ser la de moderar el fuego que allí se producía. La diferencia con el concepto fisiológico de Unanue es que, al no vincularse a una relación teleológica de la función, se pudo incorporar el conocimiento anatómico preciso después de Harvey. 
diversos componentes que ya se lograba identificar en la ciencia de la época, pero que aun no tenían una atribución funcional dentro de un nuevo esquema fisiológico diferente al galénico. Estos componentes sólidos se les interpreta así como asimilables al elemento tierra. Con relación a la 'cólera', la alusión al humor cólera es también indudable; por lo que, lo único que debe resaltarse es que, en este marco referencial galénico, Unanue incorpora de un modo nada escolástico y mas bien muy práctico los distintos elementos que la ciencia y fisiología moderna va descubriendo.

Concluye Unanue estableciendo que la influencia del clima, o como hoy denominaríamos, del ambiente, es fundamental para la salud, pues altera la constitución del organismo. Se reconoce aquí esa línea de pensamiento tan propia del neo hipocratismo que vincula y relaciona el microcosmos humano con el macrocosmos y viceversa; pero, también, un uso coherente y extensivo de los conceptos humorales, de sus equilibrios y contrastes. Según Unanue, la disposición del ser humano al comienzo del otoño es diferente de la que tiene al comienzo del verano o durante él, pues al inicio de la temporada de estío persiste el influjo beneficioso de la primavera que lo antecedió y se conserva 'humedad' suficiente para embotar el fuego del verano, es decir un juego humoral de opuestos que llega a equilibrio -y he allí la diferencia fundamental con la fisiología humoral escolástica-, como consecuencia de las influencias del ambiente. Luego, el 'fuego' del verano disminuye esa benéfica humedad y al comenzar el otoño la sangre está casi sin jugo (humedad) y por el contrario cargada de partículas térreas; por su parte, la alteración de la proporción con el humor cólera propicia que los sólidos se encuentren 'floxos y desecados'.

Hasta aquí, encontramos una explicación claramente ambientalista y una explicación científica, dentro de la coherencia de una teoría humoral, de los efectos del ambiente en el ser humano. Pero, allí no queda la explicación de Unanue; pues precisa las condiciones para la conservación de la vida que serían consecuencia del movimiento que hace circular los líquidos del cuerpo y evaporar sus partes heterogéneas. La causa de este movimiento es el calor, que es a su vez causa de vida y causa de muerte, dependiendo, en el primer caso, de que se mantenga dentro de un rango de temperaturas. La distribución del calor se hace a través del aire $¥$. La importancia de este elemento mediador en el equilibrio entre el cuerpo humano y el medio externo es tal, que Unanue llega a afirmar que si nos fuera posible mantener inalterable el aire alrededor nuestro, seríamos eternos: "Si este fluido que no cesa de bañarnos en todos los momentos del tiempo, fuera inalterable acaso seriamos eternos. Moderando la actividad del fuego, o animándolo en sus deliquios, la sangre circularía con el orden debido por todos sus conductos, y no sería perturbada la cantidad de transpiración destinada a purificarla, y formar alrededor de nosotros una peculiar atmósfera, que imitando a un blando vapor conserve flexible la circunferencia del cuerpo *. Pero sujeto a los transtornos de todos los seres criados, suele ser el origen de nuestra destrucción por sus varias calidades" ${ }^{\dagger}$.

Sería menester un estudio mucho mas detallado para identificar las distintas influencias, incluso algunas contrapuestas, en la fisiología de Unanue. Pero, con lo señalado se puede concluir que, sobre la base de una formación escolástica que signó su etapa de formación básica y que conservó como un esquema sobre el cual interpretar organizadamente la ciencia, Unanue incorpora las vertientes de la nueva filosofía y los desarrollos científicos que se incorporaron a la particular versión ibérica de la ilustración. De allí, el aparente eclecticismo que

¥ “el Ayre autor y legislador de quanto próspero o adverso acontece al cuerpo humano, arregla sus operaciones” Ob. Cit. P. 6. El término 'circunferencia del cuerpo' es intrigante; por el contexto se entiende que se refiere a una vida saludable, a un cuerpo sano. Pero, la inclusión del término circunferencia, y por extensión el de la figura del círculo, imagen del movimiento perfecto en la física y cosmología aristotélica, la hace más rica. Conceptualmente, es muy probable que el uso en Unanue sea una influencia más de su formación escolástica y Aristotélica inicial; y en ese caso, se notaría una vez más ese carácter de fidelidad y aceptación a las teorías clásicas, junto con la incorporación de nuevas teorías, cosmológicas en este caso, que las superan y relegan. Al parecer, ese es un signo constante en todos las ideas científicas de Unanue. Fuertemente afincadas en la ciencia moderna, no puede evitar sentirse muy cómodo con conceptos y términos escolásticos, los que en una peculiar convivencia hace coexistir en un mismo discurso moderno con los conceptos ya superados.

Ob. Cit. Pág.. 6-7 
algunos han indicado en la obra de Unanue y que en realidad responde a un proceso peculiar de incorporación de contenidos nuevos en un viejo cuerpo de conocimientos. Parafraseando el título de un libro sobre su obra, su fisiología es también una muestra de cambio en la continuidad.

\section{La topografía médica y la medicina geográfica. La influencia de Unanue en la medicina peruana}

La influencia de Unanue en la medicina peruana, que la historiografía local no cesa de ensalzar, fue sin embargo cuestionada, o en todo caso considerada negativa, en un breve artículo publicado hace más de 35 años por Woodham. No corresponde hacer una revisión exhaustiva de esa posición a la luz de nuevos estudios desarrollados, especialmente sobre el siglo XIX, en el Perú, y naturalmente también sobre la influencia de Unanue y su obra. Pero, sí se debe señalar que, a partir de la Topografía médica de Lima, en lo que deviene su obra principal, sería esperable que, siguiendo el ejemplo de Unanue, se desarrollaran obras similares para tan vasto y diverso territorio como el del virreinato o la naciente república. Sin embargo, no podemos ubicar en el período inmediato siguiente a las "Observaciones", ninguna obra, no digamos de la prolijidad y envergadura teórica de "Observaciones", sino simplemente que continuara la iniciada por Unanue, por lo menos hasta mediado el siglo XIX, y entonces con una perspectiva notablemente limitada. Eso no significa que la obra de Unanue no haya tenido una inmediata y decisiva influencia. Las razones por las cuales no ocurrieron los desarrollos de otras topografías en el Perú son fundamentalmente de dos tipos: en primer lugar, las convulsiones y el verdadero desastre que la guerra civil por la independencia produjo y su inmediata continuación con la anarquía y las pugnas mariscalicias; pero, en segundo lugar, la incipiente institucionalidad del colectivo científico en el país. Si bien Unanue creó a través de las Conferencias clínicas un modelo de formación médica que luego desarrollaría en el Colegio de Medicina y Cirugía de San Fernando, lo cierto es que más allá de esa institución y sus limitadas capacidades, el entorno no era favorable para el desarrollo de la institucionalidad científica. La Universidad continuó siendo un reducto de la escolástica, para luego mutar súbitamente en un foro liberal. Pero, la tradición del trabajo bajo los patrones de la nueva ciencia no se enraizaron en el país. El recuento de las observaciones que realizó Unanue para su Topografía, sólo sería retomado, y por un pequeño grupo, varias décadas después, cuando las condiciones lo permitieron. Sin embargo, la impronta de la primacía de lo ambiental continuaría siendo el eje alrededor de lo cual se desarrollaría el higienismo y la medicina geográfica, las dos vertientes en las que desembocó el trabajo de la topografías medicas. En ese sentido, la influencia de Unanue fue decisiva y continuaría siéndolo hasta bien entrado el siglo $\mathrm{XX}$.

\section{Las zonas climáticas del Perú según Unanue}

En lo que se refiere a la Geografía Médica, debe recordarse la distinción de Unanue del Perú en cuatro zonas climáticas $*$ : La primera, o ardiente, es la ubicada al pie de los Andes, hasta los 4000 pies; la temperatura varía de los 16 a los $24^{\circ}$ de Reaumur y la humedad que la caracteriza torna a estas tierras en muy productivas. "Aquí esta la patria donde llegan a su perfecta maduración las plantas americanas, y de países ardientes". La segunda zona, es la templada; se inicia a los 4,000 pies y llega hasta los 12,000; la temperatura varía entre 9 y $16^{\circ}$. "En este benigno clima, los granos y plantas europeas crecen y producen con igual fertilidad que el maíz americano; y se presenta aquel país 'feliz donde la naturaleza en sus liberalidades, o por mejor decir, en sus profusiones, copia la imagen del paraíso terrenal' (Bouguer: Figure de la terre, $\mathrm{XXX)}$ ). La tercera zona es la fría. entre los 12,000 y los 15,000 pies. "Todo lo que se produce en él es de estatura pigmea, pobre y miserable". La temperatura varía desde el punto de congelación en la estación seca de mayo a julio hasta los $8^{\circ}$ en la lluviosa; los habitantes son "una nación de esquimales, de estatura pequeña, de un color tostado por el frío, ojos pequeños y plegado al canto externo, y la frente corta y poblada de pelo". "La vegetación manifiesta igualmente la inclemencia del temperamento en que se halla. Los arbustos que

\footnotetext{
Se entiende aquí que la idea de zonas climáticas de Unanue se adapta a la diversidad peruana, pues es evidente que la distancia al Ecuador no es lo que marca las diferencias, como lo indicaba la teoría clásica, sino la posición en relación a la cordillera de los Andes, lo cual le permite indicar la existencia de las zonas que se señala.
} 
allí nacen son leñosos, resinosos y cubiertos de cortezas firmes, para que puedan sostenerse contra el frío". La cuarta zona, o glacial, va de los 15,000 a los 21,000 pies, demarca "en todo su círculo el término de la vegetación y la vida". Señala que va descendiendo su altitud, que en los trópicos ya es de 13,000 pies y a los $45^{\circ}$ de latitud es sólo de 8 o 9,000 pies y a $\operatorname{los} 60$ o $70^{\circ}$ ya toca la superficie ${ }^{\S}$.

\section{La topografía médica de Lima}

La larga influencia de la topografía medica, claro está que no en la forma descriptiva inicial, pero sí como concepto ordenador de las características de las enfermedades y de su terapéutica, es patente aún en obras fundamentales de la investigación médica peruana muy posteriores y que por cierto no se las reconoce como seguidoras de una tradición intelectual en versión nativa. Tal es el caso, a modo de ejemplo de "La Maladie de Carrión" de Odriozola $\left({ }^{25}\right)$, que publicada en las postrimerías del siglo XIX mantiene las ideas generales de la topografía médica de Unanue sobre la especificidad de las enfermedades en relación a los condicionantes ambientales. Así, luego de identificar las zonas endémicas de verruga, Odriozola ensaya una explicación de pleno carácter topográfico para esta particularidad, indicando que son las características climáticas derivadas de su condición de valles interandinos las que condicionan la endemicidad: temperatura relativamente alta, altitud moderada y sobretodo ausencia de vientos fuertes o constantes. Aunque la bacteriología ya explicaba el origen de muchas enfermedades, Odriozola, que no desconocía estos avances, pues escribe el libro durante sus estudios en París, prefiere la explicación geográfica, sin dejar de señalar que la etiología pudiera guardar relación con algún tipo de agente biológico. Llama la atención cómo, aún en pleno auge de la explicación bacteriológica, la influencia de la visión topográfica continúa. Cueto $\left({ }^{26}\right)$, que recientemente ha revisado el tema señala que Odriozola fue el introductor de la Geografía médica en el Perú. Pero, si reconocemos los antecedentes señalados, podemos interpretar que en realidad es el continuador de una tradición iniciada con las “Observaciones" de Unanue.

\section{La educación médica en Unanue}

Es imprescindible hacer una breve anotación sobre el origen de las ideas sobre la educación médica en Unanue, tema extrañamente inexistente en la considerable bibliografía que se ha dedicado al aspecto fundacional de la obra de Unanue, pero que sin duda forma parte de su pensamiento médico, pues no puede entenderse una 'conceptualización' de la medicina sin una particular forma de transmitirla. Pese a ello, al igual que al tratar sobre su vinculación con las tradiciones culturales de la época, pareciera que también se supone que súbitamente Unanue decidió realizar la reforma de la educación médica en el virreinato como un acto voluntarista y sin referentes previos. La realidad es diferente; las ideas sobre educación médica de Unanue también fueron evolucionando y se adaptaron a las condiciones de las reformas borbónicas.

La primera etapa es la que corresponde a 1792 , cuando establece las conferencias clínicas en el anfiteatro anatómico. Se ha desarrollado ampliamente el rol fundamental que asigna a la Anatomía y la concatenación cuasi silogística, con la cual, en su famoso discurso "Decadencia y restauración del Perú", establece una relación entre el desarrollo productivo del país y la enseñanza de la Anatomía. Pero, poco se ha indicado con relación a sus disposiciones sobre el desarrollo y orden en que deberán desarrollarse los cursos de las Conferencias. Al respecto, además de las minuciosas indicaciones para el desarrollo de las Conferencias " , indicó que cada una de ellas constituía una clase del curso. El orden era sistemático: "ha de seguir un curso completo, procediendo sistemáticamente por clases, órdenes, géneros, especies y variedades". La influencia de un esquema 'more botánico' es evidente, pero luego indica que el sistema para la clasificación de enfermedades será el propuesto por un británico, William Cullen (1710-1790): "respecto de que el sistema Nosológico del Doctor Cullen tiene bastante precisión y claridad, y sus obras son las más comunes que tenemos en esta especie, se arreglará a él la clasificación de las enfermedades".

$\S \quad$ “Observaciones...". CDIP. p. 47-48.

1 Las conferencias clínicas programadas tenían lugar semanalmente, los jueves a las 4 de la tarde, alternando los profesores de medicina con los de cirugía. Se concedía al menos un mes para que cada expositor preparara la suya; las conferencias sin embargo debían seguir un curso completo. 
La indicación de que "sus obras son las más comunes que tenemos en esta especie" merece ser contextualizada. Estamos a fines del siglo XVIII. Inglaterra es enemiga de España. Aún faltan años para que, luego de la invasión napoleónica, fuerzas inglesas apoyen la insurrección popular contra el invasor. El comercio con Inglaterra es limitado y, por otra parte, con Francia había existido, desde 1700 , no solo una misma dinastía reinante, sino afinidad religiosa y una notable influencia intelectual. Pese a ello, Cullen no solo era conocido en los territorios americanos sino en la metrópoli. Es evidente que la influencia del empirismo inglés y sus escuelas médicas alcanzaba también a la educación médica.

El objeto de las conferencias, tal como se seguía en la Escuela de Glasgow, donde Cullen fue catedrático, desde 1751, era la revisión sistemática y práctica de cada una de las enfermedades que asolaban a los pobladores locales, en este caso, los de Lima. Por eso, incorporaba y alternaba médicos y cirujanos, para abarcar tanto las enfermedades internas como las externas. No se agotaba allí el carácter integral que pretendía Unanue. Pues, además, al formar estas conferencias un curso ordenado según un sistema que cubriera todas las enfermedades (internas y externas) siguiendo un orden determinado ('clases, órdenes, géneros, especies y variedades'), hasta agotar la patología, se hacía evidente su carácter fundamentalmente práctico. Se buscaba formar un nuevo tipo de médico, un médico-cirujano propiamente, el cual pese a mantener la formación básica de la nosología y fisiología europeas, estaría especialmente capacitado para ser un médico local, es decir capaz de adaptar los principios generales de la terapéutica, según la experiencia práctica de los practicantes locales.

Se ha destacado que las clases fueran prácticas. Pero, eso tampoco era una innovación de Unanue; lo tomaba de Cullen, quien fue el primer profesor de Medicina que desarrollaba sus clase en la enfermería o sala del Hospital. Adoptando sus métodos, Unanue lograba varios objetivos. En primer lugar, consolidaba un núcleo de profesores, médicos y cirujanos alrededor de la idea de la particularidad del curso y el tratamiento de las enfermedades vinculadas al Clima de Lima; es decir, consolidaba un grupo de profesionales con una formación topográfica. Recordemos que el carácter periférico y dependiente de la medicina criolla contrastaba con el hecho evidente que la presentación de las enfermedades cosmopolitas, en su versión americana, bien sea por variaciones de los agentes patógenos o bien sea por diferencias inmunológicas o raciales en la población local, daba manifestaciones diferentes clínicamente, que habían conducido a un paulatino alejamiento, en mayor o menor medida, en la aplicación de las medidas terapéuticas que se utilizaba en Europa. Pese a que no existía una polémica formal o académica propiamente sobre el tema, era constante la tensión entre los médicos locales y aquellos que formados en Europa (generalmente cirujanos) ocasionalmente ejercían en Lima, desatándose en algunos casos verdaderas batallas en las que eran utilizadas todas las armas para descalificar al contrario ".

En segundo lugar, esta propuesta evidentemente se orientaba a crear un tipo de médico que pudiera resolver con mayor eficacia un número también mayor de patologías, incidiendo por consiguiente en lo que había sido su eje ordenador al proponer las reformas de la educación médica: el poblacionismo como vertebrador de la riqueza y su estrecha vinculación con la anatomía. Pero, aquí debemos detenernos, pues es evidente que el anfiteatro anatómico relacionaba anatomía con mejor medicina y esta con el aumento de población. Pero, ahora Unanue iba más allá. No bastaba la anatomía. Es más, en realidad, en las conferencia clínicas que tuvieron por lugar el anfiteatro anatómico, el aporte de la anatomía era mínimo; como su nombre lo dice, la discusión era clínica. Cabe preguntarse si estamos ante una evolución del pensamiento de Unanue, que pasa de la anatomía a la clínica como la disciplina que mejorará la medicina o es que su discurso anatómico, sobre el cual se ha construido casi todo el arquetipo de fundador de la escuela médica peruana, era solo una parte y menor por cierto de su pensamiento médico. Nos inclinamos por la segunda interpretación y, si analizamos concienzudamente la obra y su desarrollo en el tiempo, comprobaremos lo dicho.

\section{Hacia el higienismo}

Como lo indicáramos al inicio, el pensamiento médico de Unanue desde la topografía médica, \Un ejemplo es el del cirujano Petit, ver al respecto la Crónica
Médica. 
precursor de la geografía médica, se enmarca en el Higienismo que se desarrollará plenamente durante el siglo XIX. Por eso, finalmente es importante señalar el rol central que cumple en la patogénesis de las enfermedades, tal como lo entendía Unanue el concepto de miasma. Unanue entendía que las 'Constituciones' predisponen a las enfermedades agudas y, a su vez, las Constituciones varían de acuerdo a las variaciones del 'Clima'. Pero, la enfermedad se produce por la acción directa de las miasmas. Este concepto, como otros de la época, tiene una evolución que se inicia en las últimas décadas del setecientos, en relación con el avance de la química y su influjo en la medicina. Y las miasmas, de ser una especie morbosa casi inmaterial, se corporiza y en consecuencia se generan intensos esfuerzos para precisar la naturaleza de sus componentes y su comportamiento químico. JP Janin postula, en 1782 el 'carácter alcalino' de los vapores pestilenciales; Guyton de Morveau considera, por su parte, que las emanaciones pútridas son 'amoniacales'. Mientras que, para Latham Mitchill (1764-1831) representante de la escuela americana-, los miasmas son el resultado de «la acción del septon -un óxido de nitrógeno- sobre el oxígeno». Independientemente de esta pluralidad de tipificaciones, la medicina europea (en Francia e Inglaterra), desde finales del XVIII, promueve una serie de medidas terapéuticas y preventivas, principalmente la fumigación de los lugares apestados -o que corren peligro de contagiocon diversas sustancias (ácido nítrico y clorhídrico y gas cloro, habitualmente) El español Cibat observa la acción contagiosa de la fiebre amarilla por medio del viento: "El gas animal que se levanta del cuerpo de los contagiados, si no es diluido por el aire agitado, forma una neblina, que ocupa la circunferencia de los afligidos, que son su centro; del que emanan como otras tantas fuentes los vapores o miasmas contagiosos. Estos miasmas son a veces imperceptibles, como lo es el agua y demás exhalaciones que se separan de la superficie de la tierra, durante el día por la acción de los rayos solares; y así como éstos forman nubecillas más o menos densas, que si el aire está en calma se mantienen suspensas sobre los hogares de que se separaron, se ven fluctuar igualmente los miasmas contagiosos, o el gas animal alrededor de los enfermos de quienes se separa, como refieren haberlo visto varios físicos de nota muy distinguida" (A Cibat, 1804; cit. por M y JL Peset, 1972, 162-163).
Para Cibat, que escribe en 1804, el núcleo de estas 'emanaciones malignas' se ubicaría en los 'lugares de podredumbre' -cloacas, cementerios, cárceles, etc.-, que deberán ser sometidos a vigilancia, limpieza y aislamiento. Como sabemos, concordante con estas ideas Unanue y los ilustrados del Mercurio alientan y promueven el alcantarillado, la inhumación en cementerios alejados de la ciudad, entre otras medidas higiénico sanitarias.

De este modo, la generalización de las doctrinas miasmáticas, recogidas por la topografía médica, modelará la orientación de las reformas educativas y también hospitalarias que impulsa Unanue. Su insistencia, la erradicación de los focos infecciosos: alcantarillado, agua potable, cementerios, policía, son equivalentes a las que realizados en París, a partir de 1800 .

Frente al tradicional fatalismo que presidía cualquier brote epidémico y aconsejaba el socorro divino, a partir de las ideas Unanianas de Topografía Médica, Catastasis o Constituciones e identificación de Miasmas, es posible desarrollar ahora medidas de saneamiento y control. Los hospitales, que se limitaban a amontonar heridos, enfermos, contagiosos, locos, ancianos y mendigos, que por la propia naturaleza de sus enfermedades se convertían en focos de infección, son dirigidos por los médicos. Un ejemplo es la reforma del Hospital San Andrés, en la que participa Unanue. El cuidado de los enfermos es separado progresivamente de la asistencia a los menesterosos. La salud y la enfermedad se convierten en problemas centrales para los hombres de la IIustración.

El proceso ha sido descrito por Foucault (1979) como la instalación en la sociedad dieciochesca de una 'política de la salud'; política que no contempla únicamente las notables transformaciones de la profesión médica -incremento del número de facultativos, estandarización en su formación, fundación de nuevos hospitales-, sino que afecta al todo social, integrándose con una gestión económica y política que intenta racionalizar la sociedad.

Ese es el legado de Unanue. Identificar el origen de sus ideas médicas no disminuye su figura. Por el contrario, la enaltece aún más, porque demostró que la incorporación con buen criterio de las teorías que se condicen con el entorno social y ciudadano están destinadas a tener el impacto de la que a él le tocó iniciar. 


\section{Referencias bibliográficas}

1. Woodham JE. The influence of Hipólito Unanue on Peruvian Medical Science, 1789-1820: A reappraisal. Hispanic American Historical Review HAHR. 1970;50:693-714.

2. Arias-Schreiber Pezet J. La Escuela Médica Peruana (18111972), Lima: Editorial Universitaria; 1972.

3. Paz Soldán CE. Isaac Newton y los albores de la Escuela Médica Peruana. (Discurso pronunciado en la conmemoración del III centenario del nacimiento de Newton, el día 18 de diciembre de 1942). Anales de la Sociedad Peruana de Historia de la Medicina. 1943;IV(I):63-88.

4. Paz Soldán CE. Himnos a Hipólito Unanue. Lima: Instituto de Medicina Social; 1955.

5. Anderson MS. La Europa del siglo XVIII (1713-1789). México: Fondo de Cultura Económica; 1996.

6. Israel J. Radical enlightenment. Philosophy and the making of modernity 1650-1750. Oxford: Oxford University Press; 2002.

7. Feijoo y Montenegro BJ. Cartas eruditas y curiosas. 5 vol. Madrid; 1774.

8. López Piñero JM. La introducción de 1 ciencia moderna en España. Barcelona: Ariel; 1969.

9. López Piñero JM. La carta filosófica, médico química (1687) de Juan de Cabriada, punto de partida de la medicina moderna en España. Asclepio. 1965;17:207-14.

10. Zapata D. Verdadera apología de la medicina racional. Madrid; 1690.

11. García de Cortazar F. Breve Historia de España, Madrid: Alianza editorial; 1994.

12. Anes G. El siglo de las luces. Tomo IV Historia de España dirigida por Miguel Artola. Madrid: Alianza Editorial; 1996.

13. Lesaca JM. Colirio philosophico aristotélico tomístico. Madrid; 1724.

14. Biblioteca de Hipólito Unanue. Según el inventario judicial, practicado después de su muerte. An Fac Med Lima. 1955;38(3):702-8.

15. Feijoo BJ. Teatro crítico universal, Selección de Giovanni Stiffoni. Madrid: Castalia; 1986

16. Diz Gómez A. Idea y vivencia de Europa en la España del siglo XVIII. Primera parte. Madrid: Universidad Complutense de Madrid; 2005.

17. Feijóo BJ. Causas del atraso que se padece en España en orden a las ciencias naturales. Ann Chil His Med. 1960;2:181-91.
18. Feijóo BJ. De lo que sobra y falta en la enseñanza de la Medicina Ann Chil His Med. 1960;2:193-8.

19. Unanue H. Observaciones sobre el Clima de Lima y su influencia en los seres organizados, en particular el hombre. CDIP Tomo I. Los ideólogos, Volumen $8^{\circ}$ Hipólito Unanue. Lima: Comisión Nacional del sesquicentenario de la independencia del Perú; 1974.

20. Urteaga L. Ideas Medioambientales en el siglo XVIII. Naturaleza, clima y civilización. Madrid: Akal ediciones; 1992.

21. Laín Entralgo P. (Dir.). Historia Universal de la Medicina Tomo IV. Medicina Moderna. Barcelona: Salvat; 1984.

22. Lucuce P. Tratado de Cosmografía del curso matemático para la instrucción de los militares (1739-1779). Trascripción, edición y estudio introductorio de Rafael Alcalde y Horacio Capel. Colección Geocrítica Textos electrónicos, $\mathrm{N}^{\circ} 1$ Enero de 2000. disponible en: http:// www.ub.es/geocrit/tcport.htm

23. Unanue H. Precauciones para conservar la salud en el presente Otoño. En: CDIP. Tomo I. Los Ideólogos, Volumen $8^{\circ}$ Hipólito Unanue. Sección X: Publicaciones Científicas y literarias: 1. Medicina, Documento 416, Pág. 5-10. 1974.

24. Unanue H. Resultado del Pronóstico y Precauciones para el Otoño. En: CDIP. Tomo I. Los Ideólogos, Volumen $9^{\circ}$ Hipólito Unanue. Sección X: Publicaciones Científicas y literarias: 1. Medicina, Documento 418, Pág. 13-21. 1974.

25. Odriozola E. La Maladie de Carrión; ou, la verruga péruvienne. París: Carré et Naud; 1898. Existe versión castellana: La enfermedad de Carrión o Verruga Peruana. Lima: Imprenta de la Sanidad Militar; 1946.

26. Cueto M. Nationalism, Carrion's disease and Medical Geography in the Peruvian Andes. Hist Phil Life Sci. 2003;25:319-335.

Manuscrito recibido el 15 de noviembre de 2005 y aceptado para publicación el 10 diciembre de 2005.

Correspondencia: Dr. Oswaldo Salaverry García

Las Droseras 194. Lima 3, Perú

Correo-e: ossal2000@hotmail.com 